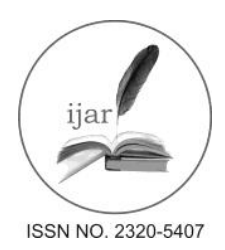

Journal homepage: http://www.journalijar.com

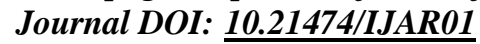

INTERNATIONAL JOURNAL

OF ADVANCED RESEARCH

RESEARCH ARTICLE

\title{
A CROSS SECTIONAL STUDY TO EVALUATE THE PREVALENCE OF SYMPTOMS OF MENOPAUSE WITH SPECIAL REFERENCE TO OSTEOPOROSIS IN POST MENOPAUSAL WOMEN ATTENDING OUT PATIENT DEPARTMENT OF A TEACHING MEDICAL INSTITUTE.
}

\author{
Tejal Poddar ${ }^{1}$, Geeta Niyogi ${ }^{2}$, Kirti Bendre ${ }^{3}$. \\ 1. Post graduate student kj somaiya medical college Mumbai ,India. \\ 2. Dean, K J Somaiya medical college Mumbai India. \\ 3. Associate Proffesor KJ Somaiya medical college Mumbai ,India.
}

\section{Manuscript Info}

\section{Manuscript History:}

Received: 14 April 2016

Final Accepted: 19 May 2016

Published Online: June 2016

Key words:

*Corresponding Author

Tejal Poddar.

\begin{abstract}
Natural menopause is defined by the World Health Organization (WHO) as the "permanent cessation of menstruation resulting from the loss of ovarian follicular activity," . The word is derived from the Greek men (month) and pausis (cessation). This cross sectional study was carried out on the women attending Out Patient Clinic of Gynaecology Department of a teaching medical institute. For this study, sample size of 373 patients was decided as per use of appropriate statistical calculations. An Osteoporosis specific score sheet was designed. A complete physical examination was conducted along with local examination for all patients which included per speculum and per vaginal examination. Special investigations were conducted for all patients to evaluate symptoms such as pap smear, breast examination and Bone Mineral Density. Bone mineral density was measured using DXA scan for the calcaneum bone. We concluded that most common symptom associated with menopausal transition was night sweats followed by muscle and joint pain , psychosexual symptoms and irritability. Bone mineral density test concluded $34.3 \%$ of the population were suffering from osteoporosis while $34 \%$ were suffering from osteopenia. There is a statistical correlation between BMD and lifestyle pattern. BMD is significantly reduced in the population suffering from symptoms muscle and joint pain. BMD is inversely proportional to the age since menopause. There is an increased risk for fractures among patients who underwent oopherectomy. There is an inverse correlation between BMD and since menopause.
\end{abstract}

Copy Right, IJAR, 2016,. All rights reserved.

\section{Introduction:-}

Natural menopause is defined by the World Health Organization (WHO) as the "permanent cessation of menstruation resulting from the loss of ovarian follicular activity," ${ }^{1}$. The word is derived from the Greek men (month) and pausis (cessation). It is the culmination of some 50 years of reproductive aging - a process which unfolds as a continuum from birth through the menopause transition and ovarian senescence. The menopause transition represents a period of dynamic changes in reproductive and non reproductive tissues. The transition from the reproductive to the non-reproductive stage is the result of a reduction in the female hormonal production by the ovaries. This transition is normally not sudden or abrupt, it tends to occur over a period of years, and it is a natural consequence of aging. However, for some women, the accompanying signs and effects that can occur during the menopause transition years can significantly disrupt their daily activities and their sense of well-being.

The overall health and well-being of middle-aged women have become a major public health concern around the world. More than $80 \%$ of the women experience physical or psychological symptoms in the years when they 
approach menopause, with various distress and disturbances in their lives, leading to a decrease in the quality of life 2

All women have more or less similar hormonal changes with menopause. However, the experience of each women is unique and is influenced by age, cultural background, health, type of menopause (spontaneous or surgical), child bearing desires and relationships. Women may view menopause as a major change in their lives either positive such as freedom from troublesome dysmenorrhoea or the need for contraception or negative such as feeling 'old' or loss of child bearing possibilities. Other women may feel that the menopause brings a cessation of sexual pleasure.

A total of 130 million Indian women are expected to live beyond the menopause into the old age by $2015 .^{3}$ Menopause is emerging as an issue owing to rapid globalization, urbanization, awareness and increase longevity in urban middle aged Indian women.

Menopause is a universal reproductive phenomenon but this reproductive landmark is not the same for all women in all cultures. The world population taken together shows a rough mean menopausal age of 40-50 years . ${ }^{4}$

As a first step towards the education of women on different aspects to menopausal symptoms and problems, one should have the insight of their problems and its preventive measures. Hence the need to assess the prevalence of menopausal problems and preventive health behaviors among selected groups of women is essential.

Menopause and osteoporosis are related to fragility fractures and constitute a major health problem, in terms of both individual suffering and financial costs. Age is also an important factor in the relationship between bone density and the absolute risk for fracture. Older women have a much higher fracture rate than younger women with the same bone density because of increasing risk from other factors, such as bone quality and tendency to fall. ${ }^{5}$ Because of the deprivation of estrogen after menopause, women are more vulnerable to bone loss than men and women with early menopause are particularly at risk.

\section{Materials and methods:-}

This cross sectional study was carried out on the women attending Out Patient Clinic of Gynaecology Department of a teaching medical institute. For this study, sample size of 373 patients was decided as per use of appropriate statistical calculations. These patients were selected by simple random sampling method. Post menopausal women beyond the age group 40 years attending the gynaecology out patient clinic were included in the study. Patients with age below 40 years or not attained menopause were excluded from the study. The study period was from January 2012 to August 2013.

Consent was taken from all the patients participating in the study .A broad Women Health questionnaire to identify mid life health problems was developed, which patients completed. This included complete history taking including age, parity, occupation ,age since menopause, past medical surgical history and specific history concerning menopausal symptoms. Subjects were graded according to their socio economic status according to the Kuppuswami classification. Lifestyle was graded as sedentary and active according to the following definition .Sedentary people were defined in two ways (1)those expending less than $10 \%$ of their leisure time expenditure in activities involving $>4$ metabolic equivalents.(2)Those who did not practice any leisure - time physical activity and who also were above the median in the number of hours spent sitting down during leisure time. Metabolic equivalents represent the ratio of energy expended during a physical activity to the metabolic rate sitting quietly, and are independent of body weight.

An Osteoporosis specific score sheet was designed. A complete physical examination was conducted along with local examination for all patients which included per speculum and per vaginal examination. Special investigations were conducted for all patients to evaluate symptoms such as pap smear, breast examination and Bone Mineral Density. Bone mineral density was measured using DXA scan for the calcaneum bone.

Inferential statistics were given by Mann Whitney test \& other tests of significance. Statistical analysis were executed to correlate between various variables. Sensitivity and specificity of each risk score were ascertained and cut off risk score for identifying osteoporosis and osteopenia were derived by comparing area under curve of each risk score on drawing receiver operational curve. Data was analysed by using SPSS Software version 16.0. 


\section{Results}

The mean age for menopause in our study was 46.21 years, median 45 years with standard deviation of 4.463 .Range (39-60) years. The mean age of our population was 52 years range (42-90years)

In our study $7.2 \%$ population had surgical menopause rest all attained natural menopause.

In our study $36.5 \%$ population had a previous medical history which included 136 persons among the study group .Rest of the population had no significant past medical history.

Table 1:- Medical co- morbid conditions in the study population.

\begin{tabular}{|l|l|l|l|}
\hline \multicolumn{2}{|c|}{} & Count & Column N \% \\
\hline \multirow{3}{*}{ Medical history } & Yes & 136 & $36.5 \%$ \\
\cline { 2 - 4 } & No & 237 & $63.5 \%$ \\
\cline { 2 - 4 } & Total & 373 & $100.0 \%$ \\
\hline
\end{tabular}

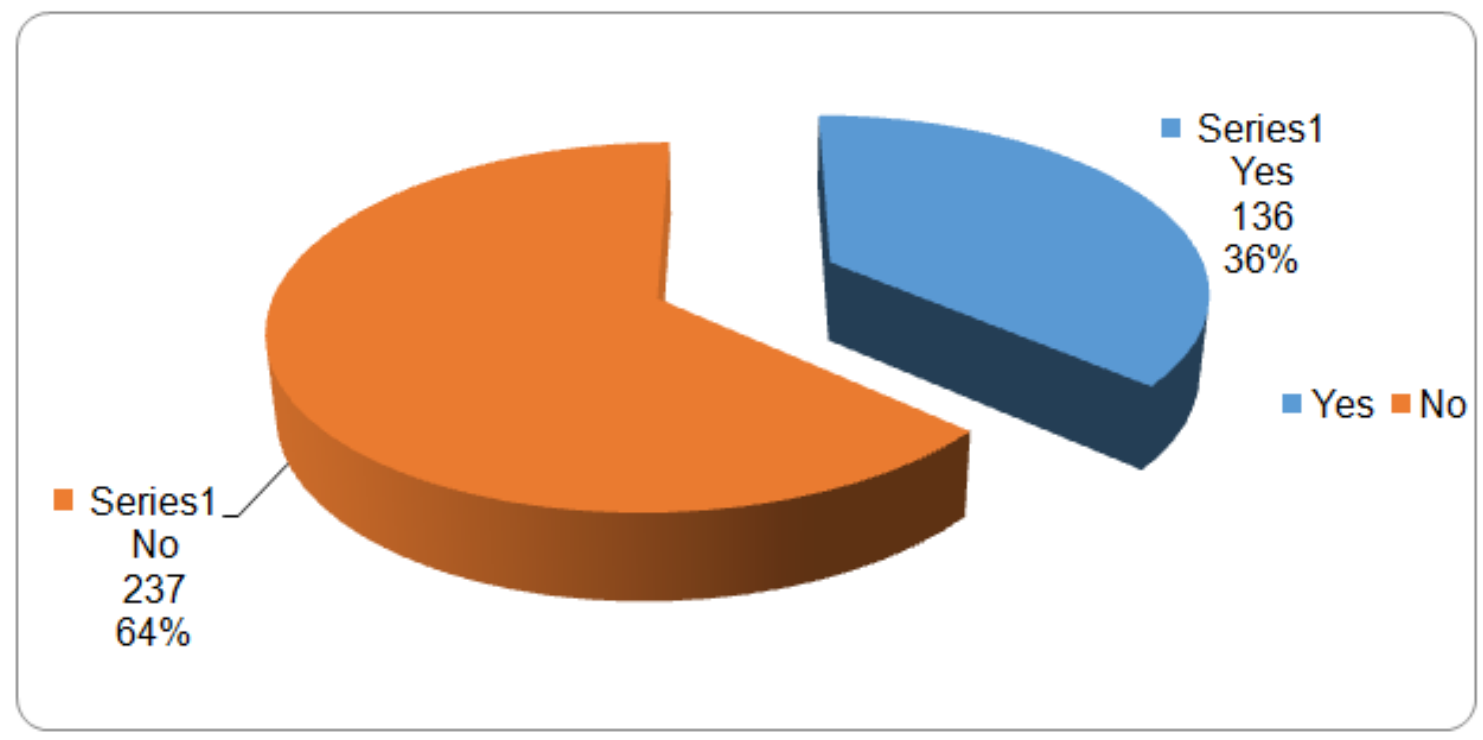

Graph 1:- Medical co- morbid conditions in the study population.

Table 2:Co- morbid conditions associated with the study population

\begin{tabular}{|l|l|l|}
\hline & Count & Column N\% \\
\hline HTN & 100 & $73.53 \%$ \\
\hline DM & 55 & $40.44 \%$ \\
\hline Heart disease & 9 & $6.62 \%$ \\
\hline Hypothyroidism & 7 & $5.15 \%$ \\
\hline Asthma & 4 & $2.94 \%$ \\
\hline Arthritis & 3 & $2.21 \%$ \\
\hline TB & 3 & $2.21 \%$ \\
\hline
\end{tabular}

Percentages exceed $100 \%$ as more than one disease was present among study subjects.

In the study maximum co-morbidity that was seen in population was hypertension $(73.53 \%)$ followed by diabetes mellitus (40.44\%) and least was seen to be arthritis (2.21\%) and tuberculosis $(2.21 \%)$. 
Series1, HTN, 100

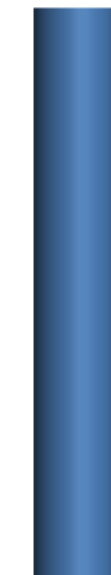

Series1, DM, 55

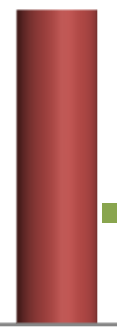

Series 1 , Hear disease, 9

Series 1 , Hypothyroidis

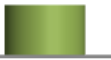

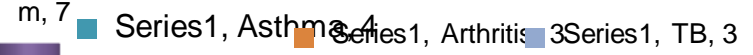

Graph 2:- Co- morbid conditions associated with the study population.

Table 3:- Percentage of population having vasomotor symptoms.

Total 259 women experienced 383 vasomotor symptoms. $51.4 \%$ had hot flushes and $96.5 \%$ had night sweats.

\begin{tabular}{|l|l|l|l|}
\hline & & Responses & Percent of Cases \\
\hline Vasomotor & & & \\
& Hot flushes & 133 & $51.4 \%$ \\
\cline { 2 - 4 } & Night sweat & 250 & $96.5 \%$ \\
\hline Total & 383 & $147.9 \%$ \\
\hline
\end{tabular}

Percentages may exceed $100 \%$

Table 4:- Percentage of population having psychological symptoms.

Total 291 women experienced 444 psychological symptoms.45.7\% had sleep disturbances, $48.5 \%$ had lethargy and $58.4 \%$ had irritability.

\begin{tabular}{|l|l|l|l|}
\hline \multicolumn{2}{|c|}{} & Responses & Percent of Cases \\
\hline \multirow{3}{*}{ Psychological } & Sleep disturbances & 133 & $45.7 \%$ \\
\cline { 2 - 4 } & Lethargy & 141 & $48.5 \%$ \\
\cline { 2 - 4 } & Irritability & 170 & $58.4 \%$ \\
\hline Total & 444 & $152.6 \%$ \\
\hline
\end{tabular}

Percentages may exceed $100 \%$

Table 5: Population having more or less than 3 symptoms.

\begin{tabular}{|l|l|l|l|}
\hline \multicolumn{2}{|c|}{} & Count & Column N \% \\
\hline \multirow{3}{*}{ More than three symptoms } & $>3$ symptoms & 194 & $52.0 \%$ \\
\cline { 2 - 4 } & $<=3$ symptoms & 179 & $48.0 \%$ \\
\cline { 2 - 4 } & Total & 373 & $100.0 \%$ \\
\hline
\end{tabular}


Table 6:- List of total number of affected population with symptoms.

Total 365 women experienced 1460 all symptoms.

In our study $36.5 \%$ population had a previous medical history which included 136 persons among the study group .Rest of the population had no significant past medical history

\begin{tabular}{|c|c|c|c|}
\hline & & Responses & Percent of Cases \\
\hline \multirow[t]{11}{*}{ All symptoms ${ }^{\mathrm{a}}$} & Hot flushes & 133 & $36.4 \%$ \\
\hline & Night sweat & 250 & $68.5 \%$ \\
\hline & Vulvovaginal & 112 & $30.7 \%$ \\
\hline & Stress incontinence & 20 & $5.5 \%$ \\
\hline & Burning micturition & 45 & $12.3 \%$ \\
\hline & Sleep disturbances & 133 & $36.4 \%$ \\
\hline & Lethargy & 141 & $38.6 \%$ \\
\hline & Irritability & 170 & $46.6 \%$ \\
\hline & Psychosexual & 174 & $47.7 \%$ \\
\hline & Weight gain & 91 & $24.9 \%$ \\
\hline & Muscle /joint pain & 191 & $52.3 \%$ \\
\hline \multicolumn{2}{|l|}{ Total } & 1460 & $400.0 \%$ \\
\hline
\end{tabular}

Table 7:- Report of Bone Mineral Density examination.

\begin{tabular}{|l|l|l|l|}
\hline \multicolumn{2}{|l|}{ BMD } & Count & Column N \% \\
\hline & Osteoporosis & 128 & $34.3 \%$ \\
\cline { 2 - 4 } & Osteopenia & 127 & $34.0 \%$ \\
\cline { 2 - 4 } & Normal & 118 & $31.6 \%$ \\
\cline { 2 - 4 } & Total & 373 & $100.0 \%$ \\
\hline
\end{tabular}

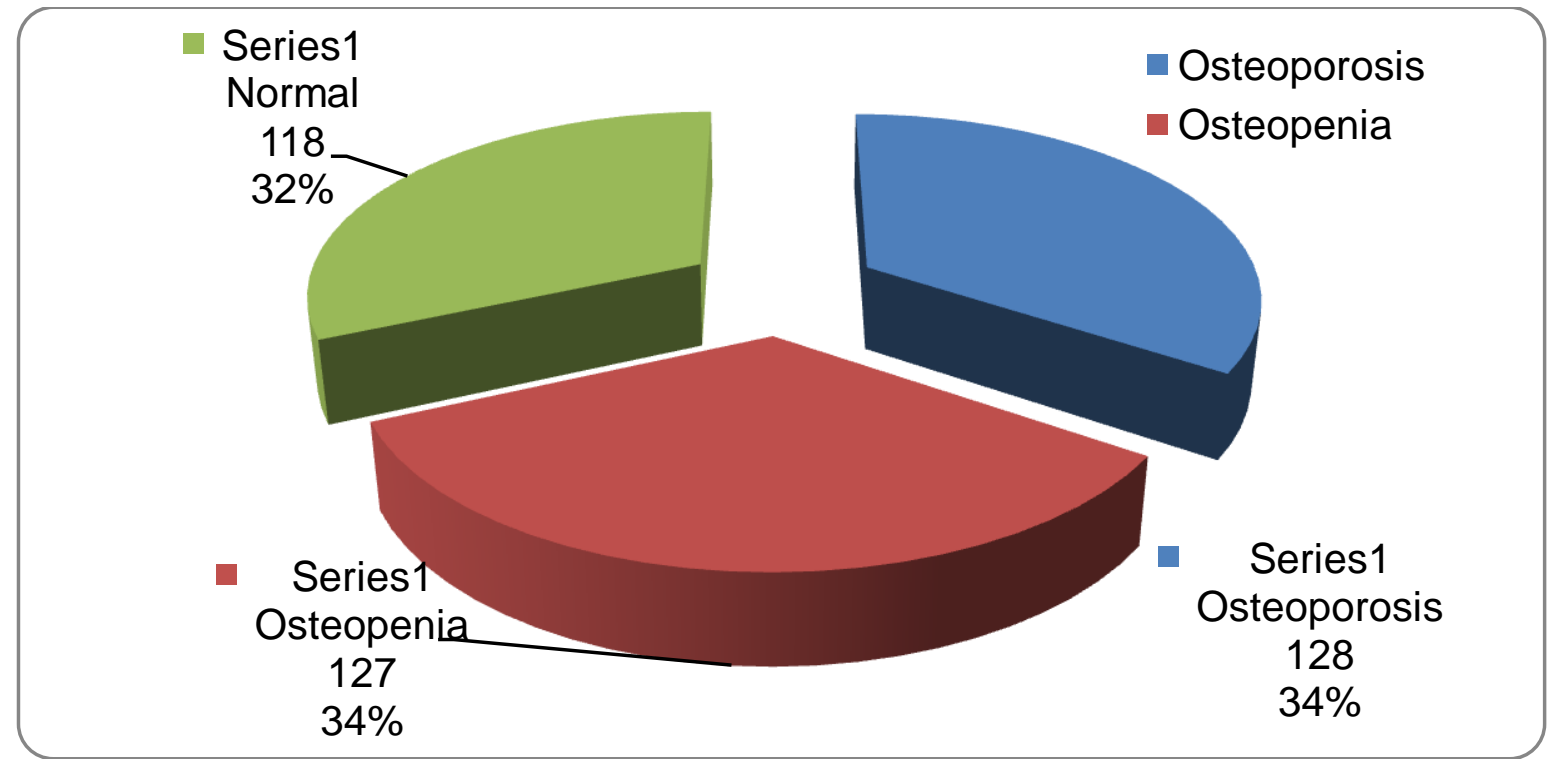

Graph 3:- Report of Bone Mineral Density examination.

Bone Mineral Density test showed that $34.3 \%$ had osteoporosis while $34 . \%$ had osteopenia rest all were normal 
Table 8:- Result of mean and standard deviation for BMD.

\begin{tabular}{|c|c|c|c|}
\hline BMD & Mean & $\mathrm{N}$ & Std. Deviation \\
\hline Osteoporosis & -2.8211 & 128 & .22047 \\
\hline Osteopenia & -1.6451 & 127 & .39867 \\
\hline Normal & .8191 & 118 & .65153 \\
\hline Total & -1.2691 & 373 & 1.56976 \\
\hline
\end{tabular}

This table shows that the mean for all osteoporotic patient BMD is -2.82 with standard deviation of 0.22 whereas for osteopenia the mean is -1.64 and standard deviation is 0.398 and for normal patients mean was 0.819 and standard deviation was 0.651

Table 9:- Distribution of BMD among patients who underwent surgical menopause.

\begin{tabular}{|l|l|l|l|}
\hline \multicolumn{2}{|l|}{} & Count & Column N \% \\
\hline Post hysterectomy & osteoporosis & 9 & $33.33 \%$ \\
\cline { 2 - 4 } & osteopenia & 10 & $37.037 \%$ \\
\cline { 2 - 4 } & normal & 8 & $29.62 \%$ \\
\hline
\end{tabular}

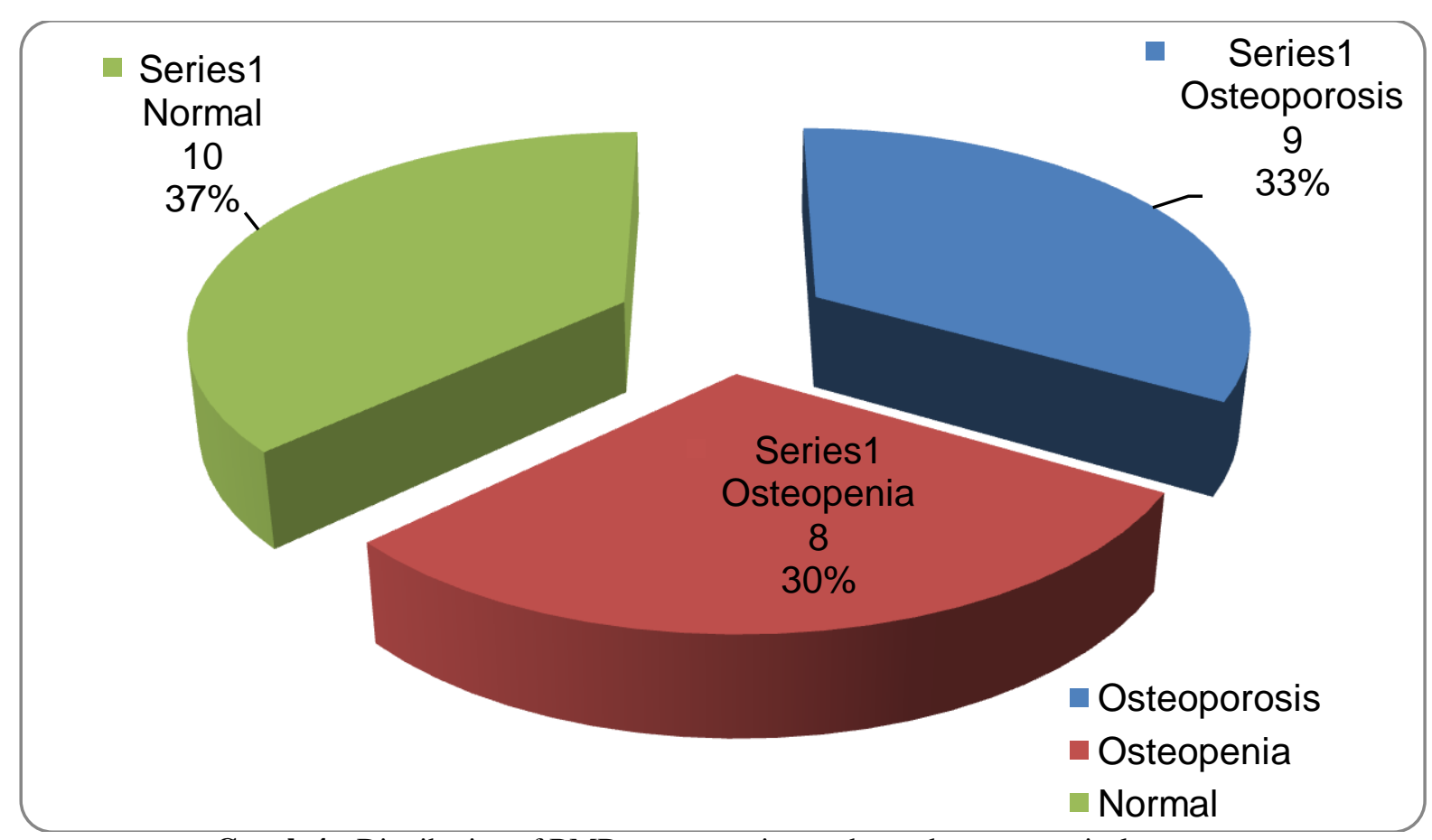

Graph 4:- Distribution of BMD among patients who underwent surgical menopause.

Among the 27 patients who had surgical menopause $33.33 \%$ population had osteoporosis $37.03 \%$ had osteopenia and $29.62 \%$ were having normal BMD scores.

Table 10:Correlation between age / BMD and age since menopause / BMD

\begin{tabular}{|l|l|l|l|}
\hline \multirow{3}{*}{ BMD } & & AGE & Age since menopause \\
\cline { 2 - 4 } & Correlation Coefficient & -.043 & $-.105^{*}$ \\
\cline { 2 - 4 } & P value & .413 & .043 \\
\cline { 2 - 4 } & $\mathrm{N}$ & 373 & 373 \\
\hline
\end{tabular}

This table shows the correlation between BMD and age which is -0.43 which means age and BMD are inversely proportional coefficients . Similar results are seen between BMD and age since menopause which is -.0105 which means they are inversely proportional coefficients..This is not statistically significant as $p$ value is 0.413 
Table 11:- Correlation between BMD and surgical menopause.

\begin{tabular}{|c|c|c|c|c|}
\hline \multicolumn{2}{|c|}{} & \multicolumn{4}{|c|}{ Ranks } \\
\hline \multirow{2}{*}{ BMD } & $\begin{array}{c}\text { Surgical } \\
\text { menopause }\end{array}$ & N & Mean Rank & Sum of Ranks \\
\cline { 2 - 5 } & Yes & 27 & 203.76 & 5501.50 \\
\hline & No & 346 & 185.69 & 64249.50 \\
\hline
\end{tabular}

This table is a correlation between surgical menopause and BMD where 27 subjects in the study group underwent surgical menopause, rest all had natural menopause. Among the 27 subjects who underwent surgical menopause 10 had osteopenia 9 had osteoporosis and 8 were normal. When this data was analyzed using Mann Whitney test, it was found that it is statistically not significant as $\mathrm{p}$ value is 0.401 .

Table 12:- Correlation between BMD and lifestyle.

\begin{tabular}{|l|l|l|l|l|l|}
\hline \multicolumn{2}{|c|}{} & \multicolumn{4}{|l|}{ LIFESTYLE } \\
\cline { 3 - 6 } \multicolumn{2}{|c|}{ Active } & Sedentary \\
\cline { 3 - 6 } \multicolumn{2}{|c|}{} & Count & Column N \% & Count & Column N \% \\
\hline \multirow{3}{*}{ BMD } & Osteoporosis & 94 & $34.6 \%$ & 34 & $33.7 \%$ \\
\cline { 2 - 6 } & Osteopenia & 97 & $35.7 \%$ & 30 & $29.7 \%$ \\
\cline { 2 - 6 } & Normal & 81 & $29.8 \%$ & 37 & $36.6 \%$ \\
\cline { 2 - 6 } & Total & 272 & $100.0 \%$ & 101 & $100.0 \%$ \\
\hline
\end{tabular}

This is a correlation between BMD and lifestyle. Among the 272 patients who had active lifestyle $34.6 \%$ hsd osteoporosis and $35.7 \%$ had osteopenia while among the 101 patients who had sedentary lifestyle $33.7 \%$ had osteoporosis and $29.7 \%$ had osteopenia. When this data was entered and analysed by Chi Square test is was found to be not significant.

Table 13:- Correlation between BMD and symptoms of muscle and joint pain.

\begin{tabular}{|l|l|l|l|l|l|}
\hline \multicolumn{2}{|c|}{} & \multicolumn{4}{|l|}{ Muscle /joint pain } \\
\cline { 3 - 6 } \multicolumn{2}{|c|}{ Absent } & Present & \multicolumn{2}{l|}{} \\
\cline { 3 - 6 } \multicolumn{2}{|c|}{} & Count & Column N \% & Count & Column N \% \\
\hline \multirow{3}{*}{ BMD } & Osteoporosis & 38 & $20.9 \%$ & 90 & $47.1 \%$ \\
\cline { 2 - 6 } & Osteopenia & 63 & $34.6 \%$ & 64 & $33.5 \%$ \\
\cline { 2 - 6 } & Normal & 81 & $44.5 \%$ & 37 & $19.4 \%$ \\
\cline { 2 - 6 } & Total & 182 & $100.0 \%$ & 191 & $100.0 \%$ \\
\hline
\end{tabular}

This table is a correlation between symptoms of muscle and joint pain and BMD. In our study group 90 patients who had muscle and joint pain were showed to have osteoporosis and 64 patients had osteopenia. On analysis of this data using Man Whitney test it was found that this was a statistically significant correlation as $\mathrm{p}$ value is 0.001

\section{Discussion:-}

The mean age at menopause observed in our study was 46.21 years. A wide range in mean age at menopause in Indian women from 40.32 to $48.84 \mathrm{yrs}^{6-15}$ and in developed countries from 48.0 to 51 yrs ${ }^{12-15}$ have been suggested in the past.

According to our study symptoms such as hot flushes ,night sweats, vulvovaginal, psychosexual and muscle and joint pain were seen maximum in low socio economic group Chowta et al., ${ }^{16}$ showed that the vasomotor symptoms were more common $(89 \%)$ in the lower socioeconomic group, Genitourinary and psychological symptoms were common in the middle socioeconomic group which were similar to our results. In agreement to our study results, the results of Kaulagekar ${ }^{17}$ showed that the high-income group had reported more vasomotor symptoms (54 vs $49 \%$ ). It also showed that the psychological symptoms were reported more (70\%) among the low-income group than the high-income group (59\%). This could be because of the several other stressors which were present in their living environment. The Study of Women's Health across the Nation (SWAN) results showed that most of the indicators of the low socioeconomic status, particularly the low educational level and the difficulty in paying for the basic necessities, were associated with a significantly increased reporting of almost all the postmenopausal symptoms. Vasomotor symptoms such as hot flushes occured in $36 \%$ of the population in our study group which were similar to 
studies conducted by Chowta et al in the year 2008 which had 42\%. Urogenital symptoms such as stress incontinence were seen in as many as $5.4 \%$ of the study group .Comparable studies showed siginificantly higher population affected by similar symptoms. Psychological symptoms such as sleep disturbances were seen in $35.7 \%$ of the study population comparable to studies conducted by Chowta et al. Lethargy as a symptom was seen in $37.8 \%$ of our study population. Other studies showed siginificantly higher population affected by this symptom. Muscle and joint pain occurred in $51.2 \%$ of the study populatation which were similar to results from other studies such as Chowta et al $(48 \%)$.

Studies conducted by Siris $\mathrm{ES}^{18}$ in the year 2001 showed that the risk for fracture increased as time since menopause increased. Relative risk for time since menopause for 10-19 years was 1.18 (1.01-1.38), 20-29 years was $1.31(1.12-1.54)$ and 30 years was $1.51(1.26-1.81)^{98}$ In our study as well relative risk for fractures increases as age since menopause increases. This is because there is a inverse correlation between BMD and since menopause

Lastly studies conducted by Tuppurainen $\mathrm{M}$ et al in the year 1995 showed that relative risk for fracture after Oophorectomy was $3.64(1.01-13.04)^{19}$ In our population 27 patients underwent surgical menopause with oopherectomy. Among them 33\% had osteoporosis and 37\% had osteopenia .Therefore there is an increased risk for fractures among patients who underwent oopherectomy.

\section{Conclusion:-}

We found that the majority of the middle aged women in our study viewed the menopausal transition as a natural process, the nature of which is affected by both hormonal changes and by ageing. Each woman seems to experience a set of psychological and physical symptoms that are in some sense unique to her experience. Hypertension was the most common co-morbid condition seen along with menopause Most common symptom associated with menopausal transition was night sweats followed by muscle and joint pain, psychosexual symptoms and irritability. Bone mineral density test concluded $34.3 \%$ of the population were suffering from osteoporosis while $34 \%$ were suffering from osteopenia. There is a statistical correlation between BMD and lifestyle pattern. BMD is significantly reduced in the population suffering from symptoms muscle and joint pain. BMD is inversely proportional to the age since menopause. There is an increased risk for fractures among patients who underwent oopherectomy. There is an inverse correlation between BMD and since menopause

\section{References:-}

1. World Health Organization. Research on the menopause in the 1990's. Report of a WHO Scientific Group. World Health Organ Tech Rep Ser. 1996;866,12-14.

2. Whelan TJ, Goss PE, Ingle JN, Pater JL, Tu DS, Pritchard K, et al. Assessment of quality of life in MA.17: a randomized, placebo controlled trial of letrozole after 5 years of tamoxifen in postmenopausal women. J Clin Oncol. 2005; 23: 6931-40.

3. Sengupta A, The emergence of the menopause in India; Central health services;2003 Jun6(2):92-5

4. Bagga, Amrita, Kulkarni, S. Age at menarche and secular trend in Indian Girls, In: Acta Biologica Szegediensis 2000: 44 (1-4): 53-57.

5. Heaney RP. Bone mass, bone loss, and osteoporosis prophylaxis. [Editorial] Ann Intern Med. 1998;128(4):313314.

6. Singh L, Ahuja S. Trend of menopause among the women of Punjab. Anthrop Anz 1980; 38:297-300.

7. Gosh AK, Kumari S. Effect of menarcheal age on fertility. J Ind Anthrop Soc 1973;8:165-172

8. Sengupta S, rjkhowa M. Menarche and menopause in Ahom women of Dibrugarh in Assam. J Hum Ecol 1996 ; 7(3) : 211-13.

9. Kaw D, Khunna B, Vasishtha K. Factors influencing the age at natural menopause. J Obstet Gynecol Ind 1994:44:273-77.

10. Mastana SS. Age at menopause among the lobanas of North West India. J Hum Ecol 1996;7(2):151-153

11. Sharma N, Singh R. Age at menarche and menopause of Brahmins and choudary females of kangra valley. Proceedings of international symposium on human growth, Patiala- India.1980

12. Kim YH, Ha EH, Shin SJ. A study on the menopausal symptoms and quality of life in middle aged women. Taehan Kanho Hakhoe Chi 2003;33(5):601-8

13. Malacara JM, Canto de Cetina T, Bassol S et al. Symptoms at pre and postmenopause in rural and urban women from three States of Mexico. Maturitas 2002; 43(1):11-9.

14. Mckinlay SM, Brambilla DJ, Possner JG. The normal menopause transition. Maturitus 1992; 14(2):103-105. 
15. Oldenhave A, Netelenbos C. Pathogenesis of climacteric complaints: ready for the changes. Lancet 1994; 343(8898):649-53.

16. Chowta NK, Sebastian J, Chowta MN. Comparative study of menopausal symptoms in post menopausal and perimenopausal women. Journal of Clinical and Diagnostic Research. 2008; 2: 959-62.

17. Kaulagekar A. Age of Menopause and Menopausal Symptoms among Urban Women in Pune, Maharashtra. J Obstet Gynaecol India. 2011; 61: 323-26.

18. Siris ES, Miller PD, Barrett-Connor E, Faulkner KG, Wehren LE, Abbott TA, et al. Identification and fracture outcomes of undiagnosed low bone mineral density in postmenopausal women: results from the National Osteoporosis Risk Assessment. JAMA. 2001;286:2815-22.

19. Tuppurainen M, Kröger H, Honkanen R, Puntila E, Huopio J, Saarikoski S, et al. Risks of perimenopausal fractures - a prospective population-based study. Acta Obstet Gynecol Scand. 1995;74:624-8. 